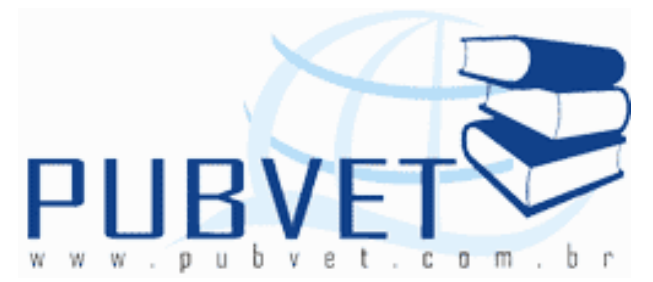

PUBVET, Publicações em Medicina Veterinária e Zootecnia.

\title{
Produção em número, peso e massa de ovos em codornas de corte até 406 dias de idade ${ }^{1}$
}

\footnotetext{
Nelson José Laurino Dionello², Victor Fernando Buttow Roll ${ }^{3}$, Eduardo Gonçalves Xavier ${ }^{3}$, Stela Adami Vayego ${ }^{4}$, Gerusa da Silva Salles Corrêa ${ }^{5}$

${ }^{1}$ Projeto financiado pelo CNPq processo 484626/2007-8;

2 Professor do DZ/FAEM/UFPel - Bolsista do CNPq;

${ }^{3}$ Professores do DZ/FAEM/UFPel;

${ }^{4}$ Professora do DEST/UFPR

${ }^{5}$ Professora do DCBPA/FAMEV/UFMT.
}

\section{Resumo}

O presente trabalho teve por objetivo estudar a produção de ovos em uma linhagem de codornas de corte sob seleção para maior peso aos 21 dias, visando verificar as características que poderiam servir como critério de seleção. Utilizaram-se modelos de regressão aleatória, trabalhando-se com variâncias residuais homogênea e heterogêneas, através de cinco modelos que contemplaram, respectivamente, períodos definidos a intervalos de 182, 112, 91, 56 e 28 dias. Na comparação entre os modelos observou-se aumento significativo $(P<0,01)$ no logaritmo natural da função de verossimilhança com o aumento das classes heterogêneas, bem como mudanças consideráveis nos outros critérios analisados (AIC e BIC), levando a consideração que a modelagem com variâncias residuais heterogêneas deva ser utilizada. 
DIONELLO, N.J.L. et al. Produção em número, peso e massa de ovos em codornas de corte até 406 dias de idade. PUBVET, Londrina, V. 5, N. 27, Ed. 174, Art. 1172, 2011.

Comparando-se os resultados entre o modelo com variância residual homogênea e o melhor modelo com variâncias residuais heterogêneas, observou-se variabilidade genética expressiva para peso de ovos com valores de 0,15 até 0,32, com variância residual homogênea e de 0,16 a 0,38 com variâncias residuais heterogêneas em períodos de 28 dias. Para número e massa de ovos os valores de herdabilidades foram similares, variando de 0,03 a 0,10 e 0,03 a 0,15, para número e de 0,01 a 0,15 e 0,01 a 0,20 para massa de ovos, respectivamente, usando-se variâncias residuais homogênea e heterogêneas. A seleção para aumento do peso de ovos seria justificada na seleção de fêmeas de codornas de corte. Para número e massa de ovos produzidos os valores embora baixos, mostraram que existem períodos em que seria viável a seleção, especialmente entre 99-126 dias e entre 211-238 dias. Os pontos de máxima produção para as três características também ficaram nestes períodos.

Palavras-chave: ambiente permanente, herdabilidades, medidas repetidas, variância residual, regressão aleatória

\title{
Egg numbers, weight, and egg mass production in meat-type quail through 58 weeks old
}

\begin{abstract}
Egg production was evaluated in a line of meat-type quail undergoing selection for increased 21-day body weight, using random regression and compares the influence of heterogeneity of residual variance on estimated genetic parameters to the growth curve of meat quails. Six models were estimated, one for homogeneous residual variance and five for heterogeneous residual variance structures, established at intervals of $182,112,91,56$, or 28 days. An increase $(P<0.01)$ of the natural logarithm of the likelihood function, by increasing the number of heterogeneous classes was observed. The model that considered homogeneity of residual variances was inadequate. Genetic variability was observed for egg weight with homogeneity of residual variance
\end{abstract}


DIONELLO, N.J.L. et al. Produção em número, peso e massa de ovos em codornas de corte até 406 dias de idade. PUBVET, Londrina, V. 5, N. 27, Ed. 174, Art. 1172, 2011.

varying from .15 to .32 and with heterogeneity varying from .16 to .38 in 13 partial (4-wk long) laying periods. Heritabilities for number of eggs laid and egg mass varied from .03 to .10 and .03 to .15 , and from 0.01 to 0.15 and .01 to .20 , respectively, with homogeneity and heterogeneity of residual variances. It is justifiable to include egg weight in the selection goals for meat-type quail. Low heritabilities values were found for egg number and egg mass but there are particular periods, especially from 99-126 days old and from 211-238 days old where selection could be effective. Peak production values for the three traits occurred between these periods.

Keywords: heritabilities, permanent environment, random regression, repeated measures

\section{INTRODUÇÃO}

O uso de modelos de regressão aleatória na avaliação genética da produção de ovos em poedeiras assemelha-se ao que tradicionalmente se usa em controle leiteiro, onde as informações de produções coletadas no dia do controle leiteiro são acumuladas para constituírem o total da produção na lactação. Dados com esta estrutura podem ser analisados sob diferentes pressuposições. Esta análise de dados longitudinais permite estimar as diferenças nas curvas de produção entre animais, essenciais para avaliação da persistência, como observado em produções leiteiras por Cobuci (2002) e Jensen (2001), e que os modelos de regressão aleatória são mais flexíveis e precisos do que o modelo de repetibilidade ou os modelos que consideram produção total ajustada para 305 dias. O uso de maior número de registros de desempenho por animal contribui para maior precisão das estimativas de seu valor genético, particularmente naquelas raças em que o controle leiteiro ainda não alcançou um adequado número de criadores e de animais. Segundo Costa et al. (2005), os estudos com modelos de regressão aleatória têm recebido uma atenção considerável nos países com programas de seleção bem estruturados. A perspectiva de uso de maior número de informações pode ser 
DIONELLO, N.J.L. et al. Produção em número, peso e massa de ovos em codornas de corte até 406 dias de idade. PUBVET, Londrina, V. 5, N. 27, Ed. 174, Art. 1172, 2011.

uma alternativa interessante, pelo potencial de maior precisão nas estimativas de valor genético e correspondente progresso genético pela seleção. Igualmente, em aves de postura esta metodologia (Anang et al., 2001 e 2002) mostrou-se vantajosa pelo uso de maior número de registros de desempenho por animal, o que por sua vez contribuiu para a maior precisão das estimativas de valor genético dos animais, particularmente ao longo da curva de produção (Szwaczkowski et al., 2006 e Luo et al., 2007). Baseando-se nestas similaridades que ocorrem entre as curvas de lactação e a de postura em aves, postula-se que a mesma metodologia possa ser utilizada na seleção de fêmeas de codornas de corte. De modo geral, o uso da metodologia revisada possibilita a obtenção de estimativas que proporcionam determinar com precisão a idade ideal para seleção, tanto para os pesos corporais quanto para a produção de ovos, em codornas de corte. As estimativas de herdabilidade encontradas na literatura para peso do ovo são consideradas de médias a altas, conforme valores obtidos por Minvielle (1998) e Mielenz et al. (2004), oscilando entre 0,35 e 0,66 . Também valores próximos são relatados por Özdemir \& Aksit (2004), que encontraram herdabilidade de 0,48 ao utilizarem dados de peso de ovo medido em várias idades, porém sem considerar o efeito ambiental permanente. Georg et al. (2009) encontraram herdabilidades para peso de ovos de 0,66, 0,52 e 0,51 para três linhagens no ambiente 1 (2900 kcal $\mathrm{EM} / \mathrm{kg}$ ) e de $0,45,0,59$ e 0,56, respectivamente, para as mesmas linhagens no ambiente $2(2500 \mathrm{kcal} \mathrm{EM} / \mathrm{kg})$. O relato de estimativas de herdabilidade para produção de ovos, característica que em alguns trabalhos (Anang et al., 2000, Szwaczkowski et al., 2006 e Luo et al., 2007), tem sido utilizada como o número absoluto de ovos, mostra baixos valores, o que denota baixa variabilidade genética nesta característica para poedeiras de modo geral. Algumas exceções são as altas estimativas encontradas com valores entre 0,21 e 0,39 por Minvielle (1998) e Mielenz et al.(2004). Georg et al. (2009) encontraram herdabilidades para produção de ovos de $0,0,0,0$ e 0,01 para as linhagens 1,2 e 3 no ambiente 1 (2900 kcal EM/kg) e de 0,0, 0,0 e 0,11, 
DIONELLO, N.J.L. et al. Produção em número, peso e massa de ovos em codornas de corte até 406 dias de idade. PUBVET, Londrina, V. 5, N. 27, Ed. 174, Art. 1172, 2011.

respectivamente para as mesmas linhagens no ambiente $2(2500 \mathrm{kcal} \mathrm{EM} / \mathrm{kg})$, usando procedimento de análise bayesiana.

O objetivo deste estudo foi avaliar a produção de ovos, em codornas de corte, até as 58 semanas de idade, por meio de modelos de regressão aleatória, visando obter maior confiabilidade das estimativas de herdabilidades e conseqüentemente maior eficiência na seleção. Igualmente, avaliou-se o comportamento de modelos propostos em função do ajuste das variâncias residuais como sendo homogênea ou heterogêneas.

\section{MATERIAL E MÉTODOS}

Foram avaliadas produções de ovos a partir dos 42 dias de idade ( 6 semanas) de 420 codornas de corte da linhagem denominada DZ/FAEM/UFPel, com controle de pedigree. As aves foram mantidas em gaiolas individuais de postura e receberam, à vontade, ração de postura para codornas (Correa et al. 2006) e água através de nipples colocados no interior das gaiolas. Foram avaliados 13 períodos de quatro semanas cada um, respectivamente denominados de P1(42-70 dias), P2(71-108 dias), P3(109-126 dias), P4(127154 dias), P5(155-182 dias), P6(183-210 dias), P7(211-238 dias), P8(239-266 dias), P9(267-294 dias), P10(295-322 dias), P11(323-350 dias), P12(351-378 dias) e P13(379-406 dias), totalizando 364 dias de avaliação de produção de ovos. Na última semana de cada período foi obtido o peso médio de ovos de cada codorna, abrangendo um período sucessivo de três dias. Também foi obtida a característica massa de ovos pelo produto do número e do peso médio de ovos, nos mesmos períodos acima. Os valores genéticos para fins de seleção foram preditos, através do programa Wombat (Meyer, 2006), utilizando-se regressão aleatória, através de um modelo animal, y = $Z_{1} a+Z_{2} p+e$, em que, y é vetor de observações de características medidas nas codornas, $Z_{1}$ e $Z_{2}$ são, respectivamente, as matrizes diagonais de incidência dos valores genéticos aditivos e de ambiente permanente, a e p são, respectivamente, os vetores de valores genéticos aditivos e ambiente 
DIONELLO, N.J.L. et al. Produção em número, peso e massa de ovos em codornas de corte até 406 dias de idade. PUBVET, Londrina, V. 5, N. 27, Ed. 174, Art. 1172, 2011.

permanente, e é o vetor de efeitos residuais. Foram testados seis modelos considerando-se em num deles variância residual homogênea (M1) e nos outros cinco, variâncias residuais heterogêneas, que contemplaram respectivamente, períodos de 182 (M2), 112 (M3), 91 (M4), 56 (M5) e 28 (M6) dias. Na comparação entre os modelos observou-se o comportamento no Teste de Razão de Verossimilhança (LRT) ao nível de $1 \%$ de probabilidade, bem como, o Critério de Informação de Akaike (AIC) e o Critério de Informação Bayesiano de Schwarz (BIC). Pelo LRT verificou-se a diferença entre os logaritmos das funções de verossimilhança restrita obtidos nos modelos, sendo que esta diferença entre os valores de $2 \log _{\mathrm{e}} \mathrm{L}$ dos modelos informa se os modelos diferem significativamente entre si. O teste baseia-se na distribuição de qui-quadrado com $g$ graus de liberdade e probabilidade de erro de $5 \%$, em que $g$ é a diferença em números de parâmetros estimados nos modelos comparados (Dobson, 1990). Avaliaram-se as mudanças ocorridas nas herdabilidades estimadas ao longo da curva de crescimento em função do ajuste de variância residual. Para as características de produções de ovos nos diversos períodos foram obtidas curvas de produção pelos polinômios de Legendre, através do programa Wombat (Meyer, 2006), sendo as informações diárias ajustadas regredidas em função da idade para obtenção das curvas de produção ajustadas.

\section{RESULTADOS E DISCUSSÃO}

Na comparação entre modelos (Tabela 1 ) pode-se observar que apesar da parametrização que ocorre ao se ajustar as variâncias residuais heterogêneas, já a partir do $M 2$ houve diferença significativa $(P<0,01)$ para o modelo em que se usou a variância residual homogênea, o qual se mostrou inadequado. Mudanças nos valores do $\log _{e} L$, AIC e BIC, significativas $(P<0,01)$ pelo $L R T$, ocorreram até o $M 6$, sugerindo que este modelo que foi trabalhado com variâncias residuais heterogêneas em períodos de 28 dias seria o de melhor ajuste. 
DIONELLO, N.J.L. et al. Produção em número, peso e massa de ovos em codornas de corte até 406 dias de idade. PUBVET, Londrina, V. 5, N. 27, Ed. 174, Art. 1172, 2011.

Tabela 1. Número de parâmetros (NP) e logaritmo da função de máxima verossimilhança (LRT) estimados para modelos com homo e heterogeneidade da variância residual para características de produção de ovos

\begin{tabular}{|c|c|c|c|c|c|c|}
\hline Modelo* & NP & $\log _{e} L^{*}$ & AIC* & BIC* & \multicolumn{2}{|c|}{ LRT** } \\
\hline \multicolumn{7}{|c|}{ Pesos de ovos } \\
\hline M1 & 13 & -2839 & 2852 & 2892 & (M2-M1) & $62 * *$ \\
\hline M2 & 14 & -2808 & 2822 & 2866 & (M3-M2) & $44 * *$ \\
\hline M3 & 15 & -2830 & 2845 & 2892 & (M4-M3) & $62 * *$ \\
\hline M4 & 16 & -2799 & 2816 & 2866 & (M5-M4) & $26 * *$ \\
\hline M5 & 18 & -2786 & 2804 & 2860 & (M6-M5) & $76 * *$ \\
\hline M6 & 24 & -2748 & 2772 & 2848 & & \\
\hline \multicolumn{7}{|c|}{ Número de ovos } \\
\hline M1 & 13 & -9388 & 9401 & 9442 & (M2-M1) & $74 * *$ \\
\hline M2 & 14 & -9351 & 9365 & 9403 & (M3-M2) & $44 * *$ \\
\hline M3 & 15 & -9373 & 9368 & 9436 & (M4-M3) & $46 * *$ \\
\hline M4 & 16 & -9350 & 9366 & 9417 & (M5-M4) & $30 * *$ \\
\hline M5 & 18 & -9335 & 9353 & 9410 & (M6-M5) & $80 * *$ \\
\hline M6 & 24 & -9295 & 9319 & 9376 & & \\
\hline \multicolumn{7}{|c|}{ Massa de ovos } \\
\hline M1 & 13 & -18754 & 18767 & 18808 & (M2-M1) & $24 * *$ \\
\hline M2 & 14 & -18742 & 18756 & 18800 & (M3-M2) & $20 * *$ \\
\hline M3 & 15 & -18752 & 18767 & 18815 & (M4-M3) & $24 * *$ \\
\hline M4 & 16 & -18740 & 18756 & 18806 & (M5-M4) & $74 * *$ \\
\hline M5 & 18 & -18703 & 18721 & 18778 & (M6-M5) & $36 * *$ \\
\hline M6 & 24 & -18685 & 18709 & 18784 & & \\
\hline
\end{tabular}

*M1 - variância residual homogênea; M2 - variâncias residuais heterogêneas para períodos de 182 dias; M3 - variâncias residuais heterogêneas para períodos de 112 dias; M4 - variâncias residuais heterogêneas para períodos de 91 dias; M5 - variâncias residuais heterogêneas para períodos de 56 dias; M6 - variâncias residuais heterogêneas para períodos de 28 dias AIC - Critério de Informação de Akaike; BIC - Critério de Informação Bayesiano de Schwarz ** $\mathrm{P}<0,01$ 
DIONELLO, N.J.L. et al. Produção em número, peso e massa de ovos em codornas de corte até 406 dias de idade. PUBVET, Londrina, V. 5, N. 27, Ed. 174, Art. 1172, 2011.

Variação dos valores de AIC e BIC foi observada por outros autores, como Bonafé et al. (2008), testando modelos de regressão aleatória com variâncias residuais homo e heterogêneas em pesos corporais de codornas de corte e por Szwaczkowski et al. (2006), que utilizaram diversos modelos sob variância residual homogênea para produção de ovos em galinhas.

Considerando-se os modelos de variância residual homogênea e o melhor modelo de variâncias residuais heterogêneas (M6), de modo geral para todas as características os valores de herdabilidades mostraram leve aumento quando se utilizou as variâncias residuais heterogêneas, especialmente entre os períodos P3 e P7 (Tabela 2). Os valores para peso de ovos variaram de 0,15 até 0,32, com variância residual homogênea e de 0,16 a 0,38 com variâncias residuais heterogêneas (M6) em períodos de 28 dias. Para número e massa de ovos os valores de herdabilidades foram similares, variando de 0,03 a 0,10 e 0,03 a 0,15, para número e de 0,01 a 0,15 e 0,01 a 0,20 para massa de ovos, respectivamente usando-se variâncias residuais homogênea ou heterogêneas (M6). As estimativas obtidas para peso de ovos foram semelhantes às obtidas por Saatci et al. (2006) que encontraram herdabilidade de 0,25, abaixo dos valores relatados por Minvielle (1998) e Mielenz et al. (2004), entre 0,35 e 0,66, e de Özdemir \& Aksit (2004), que encontraram herdabilidade de 0,48 ao utilizarem informações de peso de ovo medido em várias idades, porém sem considerar efeito permanente. Igualmente, os valores são menores que os obtidos por Georg et al. (2009), de 0,66, 0,52 e 0,51 para as linhagens 1 , 2 e 3 no ambiente 1 (2900 kcal EM/kg) e de 0,45, 0,59 e 0,56, respectivamente, para as mesmas linhagens no ambiente 2 $(2500 \mathrm{kcal} \mathrm{EM} / \mathrm{kg})$. As estimativas de herdabilidades para produção de ovos e massa de ovos foram baixas, sendo levemente mais altas para massa de ovos em ambos os modelos (Tabela 2), o que sugere baixa variabilidade genética nessas características para codornas, como também ocorre em galinhas poedeiras. As estimativas são inferiores às encontradas com valores entre 0,21 e 0,39 por Minvielle (1998), Mielenz et al.(2004) e por Luo et al. (2007), que, estudando o número de ovos acumulado do início da maturidade sexual até 40 
DIONELLO, N.J.L. et al. Produção em número, peso e massa de ovos em codornas de corte até 406 dias de idade. PUBVET, Londrina, V. 5, N. 27, Ed. 174, Art. 1172, 2011.

semanas de idade em aves de postura, utilizando polinômios de Legendre para modelar a curva de produção, encontraram estimativas de herdabilidade que variaram de 0,16 a 0,54. Entretanto, de modo geral, estão acima dos valores obtidos no caso da produção de ovos por Georg et al. (2009) que encontraram herdabilidades de 0,0,0,0 e 0,01 para as linhagens 1,2 e 3 no ambiente 1 (2900 kcal EM/kg) e de 0,0, 0,0 e 0,11, respectivamente, para as mesmas linhagens no ambiente $2(2500 \mathrm{kcal} \mathrm{EM} / \mathrm{kg})$, usando procedimento de análise bayesiana.

Os maiores valores de herdabilidade para peso de ovos estiveram entre os períodos $\mathrm{P} 5$ e $\mathrm{P} 8$, o que comparativamente se aproxima dos períodos entre P3 e P7, nos quais se observou os valores mais altos de herdabilidade para número e massa de ovos. A consideração destes períodos (P3 a P7) seria importante para seleção das aves visando ganhos genéticos nestas características. Estes resultados diferem dos obtidos em poedeiras por Luo et al. (2007), que encontraram valores maiores de herdabilidades até 10 semanas de produção, enquanto que da décima segunda a vigésima semana de produção, as estimativas de herdabilidades foram moderadas, recomendando que a seleção baseada no número de ovos acumulados deva ser realizada nas primeiras semanas de produção de ovos. Para massa de ovos foram observados resultados que, em comparação aos obtidos para as outras duas características, situam essa característica com valores intermediários para as herdabilidades. Como estratégia de seleção, a recomendação pode ser em primeiro usar o peso de ovos e em segunda ordem massa de ovos, que se mostrou levemente superior ao número de ovos, nos valores de herdabilidades obtidas. 
DIONELLO, N.J.L. et al. Produção em número, peso e massa de ovos em codornas de corte até 406 dias de idade. PUBVET, Londrina, V. 5, N. 27, Ed. 174, Art. 1172, 2011.

Tabela 2. Herdabilidades para peso, número e massa de ovos para os modelos considerando variâncias residuais homogênea e heterogêneas*

\begin{tabular}{|c|c|c|c|c|c|c|c|}
\hline & & & & $\begin{array}{c}\text { Peso de } \\
\text { ovos }\end{array}$ & & & \\
\hline & $\mathrm{P} 1 * *$ & $\mathrm{P} 2$ & P3 & P4 & P5 & P6 & P7 \\
\hline \multirow[t]{2}{*}{ M1/M6 } & $0,26 / 0,25$ & $0,27 / 0,27$ & $0,29 / 0,37$ & $0,30 / 0,29$ & $0,32 / 0,32$ & $0,32 / 0,38$ & $0,32 / 0,36$ \\
\hline & P8 & P9 & P10 & P11 & P12 & P13 & \\
\hline \multirow[t]{3}{*}{ M1/M6 } & $0,32 / 0,30$ & $0,30 / 0,22$ & $0,27 / 0,27$ & $0,24 / 0,16$ & $0,19 / 0,21$ & $0,15 / 0,16$ & \\
\hline & & & & $\begin{array}{c}\text { Número de } \\
\text { ovos }\end{array}$ & & & \\
\hline & P1 & P2 & P3 & P4 & P5 & P6 & P7 \\
\hline \multirow[t]{2}{*}{ M1/M6 } & $0,07 / 0,08$ & $0,08 / 0,08$ & $0,09 / 0,14$ & $0,09 / 0,15$ & $0,10 / 0,13$ & $0,09 / 0,14$ & $0,09 / 0,12$ \\
\hline & P8 & P9 & P10 & P11 & P12 & P13 & \\
\hline \multirow[t]{3}{*}{ M1/M6 } & $0,07 / 0,08$ & $0,06 / 0,07$ & $0,04 / 0,06$ & $0,03 / 0,04$ & $0,03 / 0,03$ & $0,04 / 0,04$ & \\
\hline & & & & $\begin{array}{c}\text { Massa de } \\
\text { ovos }\end{array}$ & & & \\
\hline & $\mathrm{P} 1$ & $\mathrm{P} 2$ & P3 & P4 & P5 & P6 & P7 \\
\hline \multirow[t]{2}{*}{ M1/M6 } & $0,05 / 0,04$ & $0,09 / 0,07$ & $0,12 / 0,17$ & $0,14 / 0,20$ & $0,15 / 0,15$ & $0,15 / 0,18$ & $0,13 / 0,15$ \\
\hline & P8 & P9 & P10 & $\mathrm{P} 11$ & P12 & P13 & \\
\hline M1/M6 & $0,11 / 0,09$ & $0,08 / 0,07$ & $0,05 / 0,05$ & $0,02 / 0,01$ & $0,01 / 0,01$ & $0,01 / 0,01$ & \\
\hline
\end{tabular}

*M1 - variância residual homogênea; M2 - variâncias residuais heterogêneas períodos de 28 dias

**P1(42-70dias)； P2(71-108dias)； P3(109-126dias)； P4(127-154dias)； P5(155-182dias)； P6(183-210dias); P7(211-238dias)； P8(239-266dias)； P9(267-294dias)； P10(295-322dias); P11(323-350dias); P12(351-378dias) e P13(379-406dias) 
DIONELLO, N.J.L. et al. Produção em número, peso e massa de ovos em codornas de corte até 406 dias de idade. PUBVET, Londrina, V. 5, N. 27, Ed. 174, Art. 1172, 2011.

\section{Produção em número de ovos}

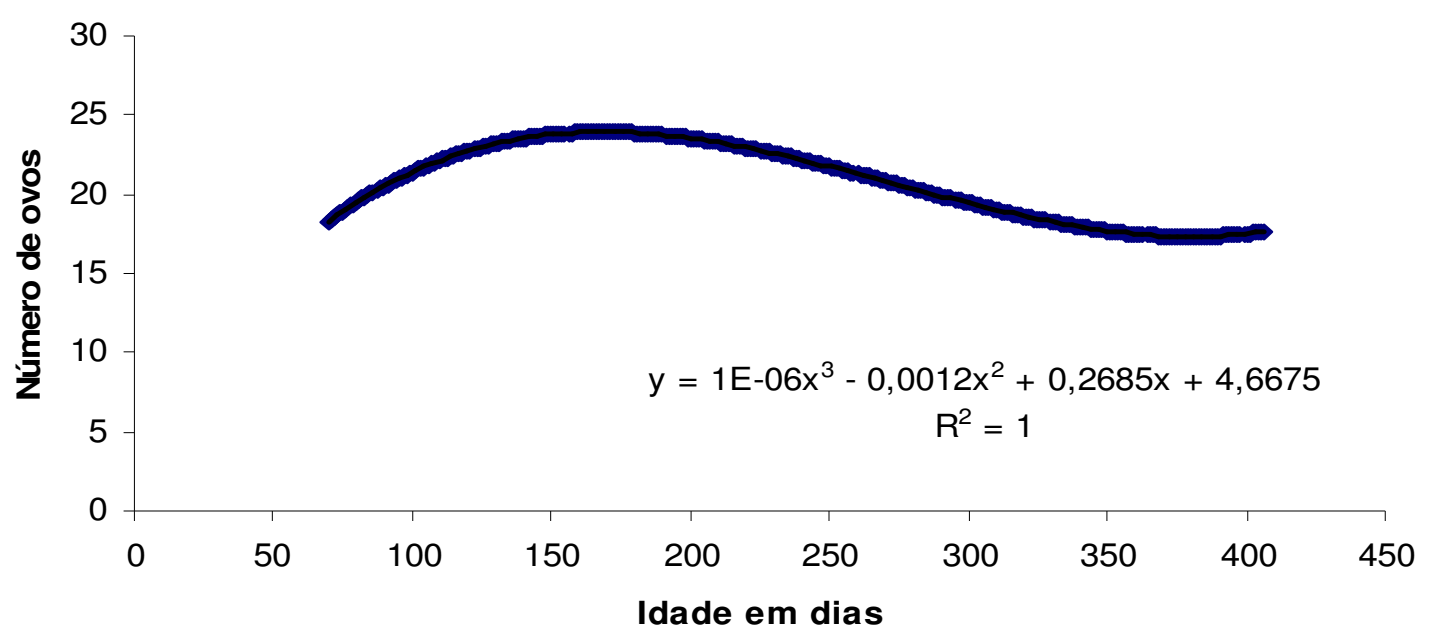

Figura 1 - Curva de produção de ovos em codornas de corte de 42 a 406 dias

A curva de produção em número de ovos (Figura 1) de 42 até 406 dias de idade das codornas avaliadas individualmente, apresentou-se diferente da curva de produção de ovos de galinhas, com um leve pico de postura e um conseqüente período de manutenção de produção de menor intensidade. Houve um ajustamento cúbico para todas as características, sendo que para número de ovos o pico de produção situou-se aos 133 dias ou 19 semanas (ponto de máximo da função cúbica ajustada) com um sucessivo declínio, situando-se o ponto de máximo dentro do P4 (127-154 dias ou 19-22 sem).

Obteve-se o ponto de maior peso de ovos (Figura 2) aos 189 dias (27 semanas), pouco adiante do ponto de pico de postura obtido de 133 dias (19 semanas), estando esse ponto dentro do P6 (182-210 dias ou 27-30 semanas). 
DIONELLO, N.J.L. et al. Produção em número, peso e massa de ovos em codornas de corte até 406 dias de idade. PUBVET, Londrina, V. 5, N. 27, Ed. 174, Art. 1172, 2011.

\section{Peso de ovos produzidos}

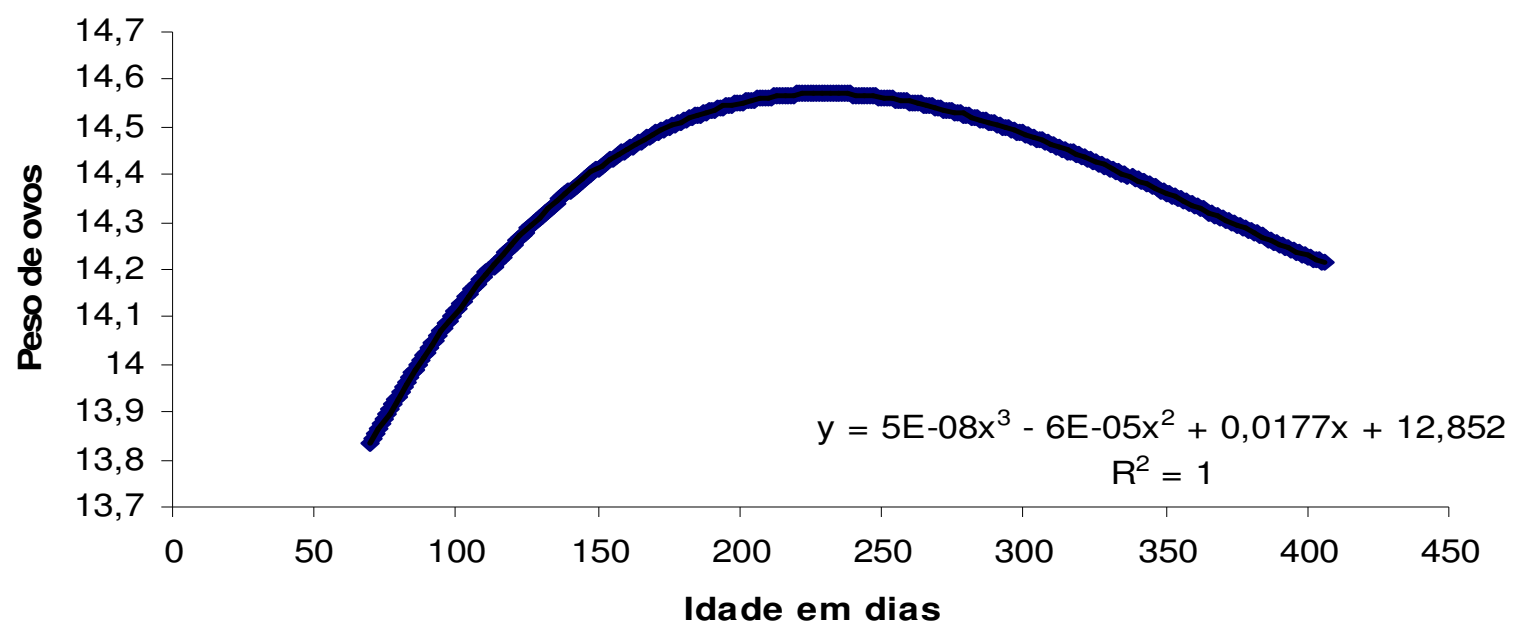

Figura 2. Curva de peso de ovos em codornas de corte de 42 a 406 dias

\section{Massa de ovos produzida}

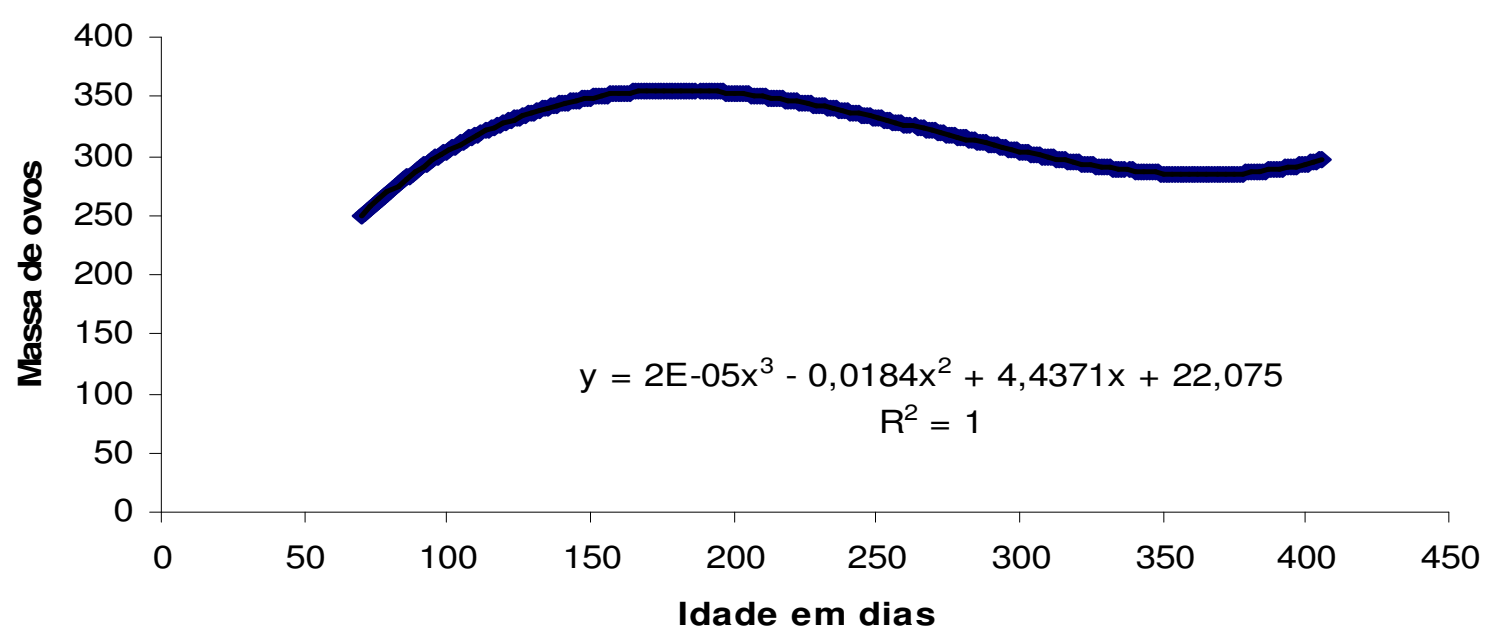

Figura 3. Curva de massa de ovos produzida em codornas de corte de 42 a 406 dias 
DIONELLO, N.J.L. et al. Produção em número, peso e massa de ovos em codornas de corte até 406 dias de idade. PUBVET, Londrina, V. 5, N. 27, Ed. 174, Art. 1172, 2011.

Para a massa de ovos (Figura 3) foi obtido o ponto de máxima produção aos 166 dias (23,7 semanas), dentro do período P5 (155-182 dias ou 23-26 semanas).

De modo geral as estimativas mais altas tanto para os parâmetros genéticos como para os valores produtivos foram obtidos até no máximo o P8 (183-219 dias) o que justificaria em trabalhos futuros o uso do período de avaliação visando à seleção em codornas de corte até esta idade de 266 dias.

\section{CONCLUSÕES}

Para as variâncias residuais é recomendável a utilização do ajuste com uso da heteroscedasticidade para características de produção de ovos em codornas de corte. Entre as características avaliadas para o peso de ovos observa-se importante variabilidade genética justificando o uso desta característica na seleção de fêmeas de codornas de corte. Para número e massa de ovos produzidos as herdabilidades são baixas, mostrando que existem períodos em que seria recomendável a seleção (109-238 dias) e onde igualmente situam-se os pontos de máxima produção para as três características.

\section{AGRADECIMENTOS}

Ao Conselho Nacional de Desenvolvimento Científico e Tecnológico (CNPq) e ao Programa de Pós Graduação em Zootecnia da Universidade Federal de Pelotas, pelo suporte financeiro. Ao Prof. Frank Siewerdt, University of Maryland (USA) pelos comentários e sugestões apresentados. 


\section{REFERÊNCIAS BIBLIOGRÁFICAS}

ANANG, A.; MIELENZ, N.; SCHÜLER, L. Genetic and phenotypic parameters for monthly egg production in White Leghorn hens. J. Anim. Breed. Genet., v.117, p.407- 415, 2000.

ANANG, A.; MIELENZ, N.; SCHÜLER, L. Monthly model for genetic evaluation of laying hens 1. Fixed regression. Brit. Poultry Sci., v. 42, p. 191-196, 2001

ANANG, A.; MIELENZ, N.; SCHÜLER, L. Monthly model for genetic evaluation of laying hens 2. Random regression. Brit. Poultry Sci., v. 43, p. 384-390, 2002

BONAFÉ, C.M.; TEIXEIRA, R.B.; SOUZA, M.F. et al. Modelos de regressão aleatória considerando heterogeneidade de variâncias residuais na descrição de curva de crescimento de codornas européias. In: REUNIÃO ANUAL DA SOCIEDADE BRASILEIRA DE ZOOTENIA, 45, 2008, Lavras. Anais... Lavras, 2008. CD ROM.

COBUCI, J.A. Uso de modelos de regressão aleatória na avaliação da persistência na lactação de animais da raça holandesa. Viçosa, MG: Universidade Federal de Viçosa, 2002, 99p. Tese (Doutorado em Zootecnia) - Universidade Federal de Viçosa, 2002.

CORRÊA, G.S.S.; SILVA, M.A.; CORRÊA, A.B. et al. Exigência de metiona + cistina para codornas de corte em crescimento. Arquivo de Medicina Veterinária e Zootecnia, v.58, n.3, p. 414-420, 2006.

COSTA, C.N.; MELO, C.M.R.; MACHADO, C.H.C. et al. Parâmetros genéticos para a produção de leite de controles individuais de vacas da raça Gir estimados com modelos de repetibilidade e regressão aleatória. R. Bras. Zootec., v.34, p. 1520 - 1531, 2005.

DOBSON, A.J. An introduction to generalized linear models. Melbourne: Chapman and Hall, 1990. 174p.

GEORG, P.C.; PAIVA, E.; CONTI, A.C.M. et al. Interação genótipo $\times$ ambiente em codornas de postura alimentadas com rações com dois níveis de energia metabolizável. R. Bras. Zootec., v.38, n.9, p. $1706-1711,2009$.

JENSEN, J. Genetic evaluation of dairy cattle using test day models. Journal of Dairy Science, v.84, n.12, p.2803-2812, 2001.

LUO, P.T.; YANG, R.Q.; YANG, N. Estimation of genetic parameters for cumulative egg numbers in a broiler dam line by using a random regression model. Poultry Sci., v.86, p.30, 2007.

MEYER, K. "Wombat"- a program for mixed model analyses by restricted maximum likelihood. University of New England. Armidale, Australia. 2006. 66p.

MIELENZ, N.; NOOR, R.R.; SCHÜLER, L. Estimation of additive and non-additive genetic variances of body weight, egg weight and egg production in quail, using animal models. In: WORLD'S POULTRY CONGRESS, 22., 2004, Istanbul. Proceedings... Istanbul: Turkey. World's Poultry Congress \& Exibition, [2004]. (CD-ROM).

MINVIELLE, F. Genetics and breeding of japanese quail for production around the world. In: ASIAN PACIFIC POULTRY CONGRESS, 6., 1998, Nagoia. Proceedings... Nagoia: Japan Poultry Science Association, 1998. p.122-127. 
ÖZDEMIR, D.; AKSIT, M. Estimations of genetic parameters of some egg quality characteristics of Japanese quails (Coturnix coturnix japonica) at different ages. In: WORLD'S POULTRY CONGRESS, 22., 2004, Istanbul. Proceedings... Istanbul:World's Poultry Congress \& Exibition, [2004]. (CD-ROM).

SAATCI, M.; OMED, H.; DEWI, I.Ap. Genetic parameters from univariate and bivariate analyses of egg and weight traits in Japanese quail. Poultry Science, v.85, p. 185-190, 2006.

SZWACZKOWSKI, T.; WOLC, A.; LISOWSKI, M. Genetic evaluation in laying hens based on fixed and random regression models. In: WORLD CONGRESS ON GENETICS APPLIED TO LIVESTOCK PRODUCTION, 8, 2006, Belo Horizonte, Brasil. Proceedings... Belo Horizonte, Brasil, 2006. CD-ROM. 